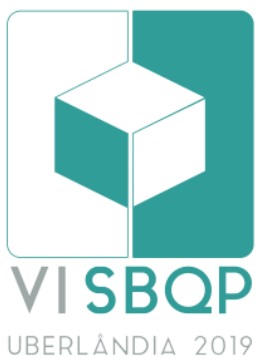

\title{
INTEGRAÇÃO ENTRE FERRAMENTAS DE ANÁLISE E AVALIAÇÃO DE PROJETO
}

\author{
GARCIAS, Elcio de Oliveira \\ Universidade Federal de Uberlândia, PPGAU, e-mail: elcio.arq@gmail.com \\ RIBEIRO, Patrícia Pimenta Azevedo \\ Universidade Federal de Uberlândia, PPGAU, e-mail: pparibeiro@ufu.br
}

\begin{abstract}
RESUMO
Este artigo é fruto do levantamento teórico desenvolvido para o projeto de pesquisa sobre o Centro Administrativo de Uberlândia elaborado para a dissertação do programa de Pósgraduação em Arquitetura e Urbanismo da Universidade Federal de Uberlândia. O estudo tem como objetivo a integração entre análise de projeto e avaliação de desempenho. Inicialmente se esclarece a diferença entre análise e avaliações para em seguida propor uma colaboração entre ferramentas e metodologias destas duas áreas com o objetivo de um entendimento mais abrangente de uma obra arquitetônica.
\end{abstract}

Palavras-chave: Análise de projeto, Avaliação espacial, Avaliação de projeto, Ensino de arquitetura, Centro Administrativo de Uberlândia

\begin{abstract}
This article is the result of the theoretical study developed for the research project on the Centro Administrativo de Uberlândia prepared for the dissertation of the Post-graduate program in Architecture and Urbanism of the Universidade Federal de Uberlândia. Here we address the issue of integration between project analysis and performance evaluation. Initially the difference between analysis and evaluations is clarified, and then a collaboration between tools and methodologies of these two areas is proposed, aiming at a more comprehensive understanding of an architectural work.
\end{abstract}

Keywords: project analysis, spatial evaluation, project evaluation, architecture teaching

\section{INTRODUÇÃO}

A pesquisa na área de arquitetura e urbanismo tem por objetivo atender a diversas finalidades, Malard (2005, p. 94) observa que "sendo a arquitetura um campo de aplicação, o nosso objetivo como pesquisadores deverá ser o de gerar conhecimentos que os arquitetos possam aplicar para fazerem melhores projetos." Colocando em outras palavras, é o fornecimento de subsídios que norteiem o processo de projeto.

Miranda esclarece que este processo não deriva apenas de uma atenção ao atendimento do programa, a hipótese funcionalista, e tão pouco ao uso de tipologias já existentes, a hipótese tipológica.

[...] formas não são derivadas primordialmente de preceitos e teorias, como também não o são resultado das limitações e

GARCIAS, E. O.; RIBEIRO, P. P. A. Integração entre ferramentas de análise e avaliação de projeto. In: SIMPÓSIO BRASILEIRO DE QUALIDADE DO PROJETO NO AMBIENTE CONSTRUÍDO, 6., 2019, Uberlândia. Anais... Uberlândia: PPGAU/FAUeD/UFU, 2019. p. 1260-1272. DOI https://doi.org/10.14393/sbqp19115. 
requerimentos de um projeto. Formas são derivadas de outras formas. O arquiteto agencia o que the é disponível, o que conhece, a partir de uma interpretação da situação singular que enfrenta (MIRANDA, 2011 , p. 4).

Além disso, essas pesquisas contribuem para a formação de uma cultura arquitetônica e consequentemente para a difusão do conhecimento entre os profissionais da área, notadamente os arquitetos e urbanistas.

Colocando dessa forma, tem-se a impressão de que ela está ligada diretamente a prática profissional, no entanto, ela também tem uma ligação direta com o ensino do projeto. Como aponta Mahfuz (2013) em "Banalidade ou correção: dois modos de ensinar arquitetura e suas consequências", o contato de estudantes com obras excepcionais de arquitetura é também uma importante ferramenta de ensino de projeto.

Estes subsídios podem vir através de vários tipos de pesquisa, sendo as análises de projeto ou avaliações de pós-ocupação bastantes usadas. No entanto, o enfoque comumente recai apenas sobre uma delas, fazendo com que ou se analise apenas o processo de concepção do projeto ou o desempenho da obra executada. Nem sempre as transformações pelas quais o projeto passa desde sua concepção a execução. Esta união propiciaria não apenas um saber, mas também um entendimento mais abrangente de como as ideias e soluções de projeto evoluem ao longo das etapas de projeto, execução e uso. Entendendo evolução aqui como transformações e não um simples refinamento linear de uma ideia.

\section{METODOLOGIA}

Análise e avaliações possuem enfoques diferentes. As primeiras são voltadas para o entendimento do projeto em si, ou seja, como suas partes se relacionam, tanto no que diz respeito ao programa quanto a composição e organização espacial. Como exemplo pode-se citar as propostas de Análise de Projeto de autores como Bernard Leupen e Geoffrey Baker. Já as avaliações, enfocam no desempenho do edifício, e estas podem abranger questões ligadas ao conforto do edifício, incorporando aí questões de conforto térmico, acústico, luminoso, e também questões mais subjetivas, como a percepção do usuário dentro daquele espaço. Estas avaliações normalmente estão agrupadas sobre o que se convencionou chamar de Avaliações Pós-Ocupação (APO), e tem como uma das principais características trazer o usuário para dentro do processo de avaliação. Apesar de enfoques diferentes, pode se dizer que de certa forma há uma complementaridade entre elas.

Com o intuito de abordar a questão da integração entre análise de projeto e avaliação de desempenho, parte-se inicialmente da definição de cada uma dessas modalidades, para em seguida propor um modo de integrar ferramentas e metodologias destas áreas.

Neste sentido, estabelece-se uma discussão acerca da integração entre ferramentas de análise de projeto e avaliações pós-ocupação, tendo como estudo de caso o Centro Administrativo de Uberlândiai (tema da pesquisa de mestrado que deu origem a este artigo), sendo que aqui o enfoque recairá sobre apenas a praça delimitada pelo Gabinete do prefeito e a Câmara dos 
vereadores, por entender que a mesma ilustra bem as propostas aqui apresentadas.

\subsection{Análise de projeto}

Resumidamente pode-se descrever as análises de projeto como uma busca pelo entendimento de como o programa e suas partes são articuladas. Recriando o projeto omitindo ou acrescentando informações, para assim, estabelecer relações entre os diversos tipos de tecnologias e interações presentes. Segundo Leupen et al. (1999): "Um caminho para compreender a fundo o processo de projeto é o de analisar a obra resultante", ato este designado por ele através de expressão "análise de projeto".

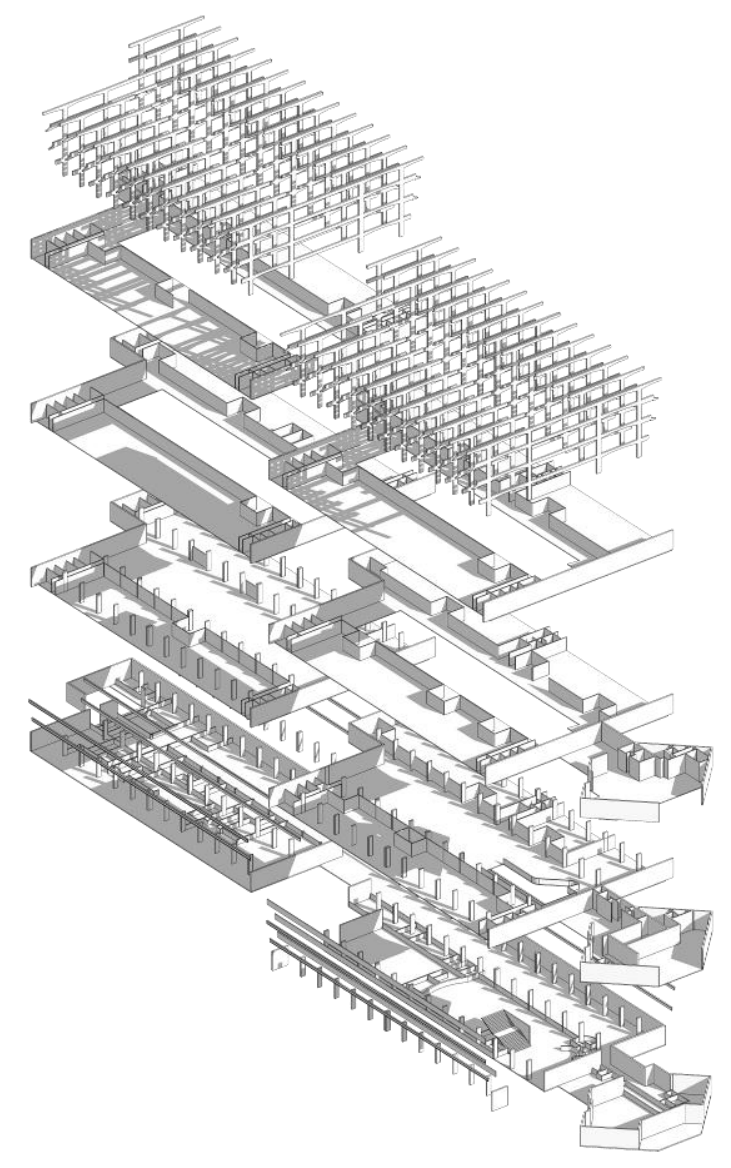

\section{Figura 1 - Exemplo "explodido" do edifício do bloco Executivo do Centro Administrativo de Uberlândia - Fonte: Autor (2019)}

Como aponta Conde (2006, p. 4), há vários autores com reconhecidos trabalhos acadêmicos nesta área, como por exemplo: Geoffrey Baker, Simon Unwin, Francis Ching, Hideaki Haraguchi entre outros. No entanto, como esclarece o próprio Conde (2006, p. 131), nota-se nos autores acima citados, uma "significativa ausência na investigação da relação do edifício com o lugar [...] A negligência a assuntos relativos ao sistema construtivo e ao sistema estrutural também é verificada". Em virtude disso optou-se pela abordagem de Bernard Leupen por considerá-la mais abrangente, abordando como será 
explicado a frente, questões relativas à ordem e composição, uso, estrutura, tipologia e contexto.

Essa abordagem é apresentada no livro Design and Analysis, elaborado por Bernard Leupen em conjunto com Christoph Grafe, Nicola Körnig, Marc Lampe e Peter de Zeeuw. Foi originalmente publicado em alemão, em 1993, e posteriormente recebeu uma versão em inglês em 1997. A proposta desse livro é explorar os diversos aspectos de leitura e análise de uma obra arquitetônica. Como descrito anteriormente, estes aspectos envolvem ordem e composição, uso, estrutura, tipologia e contexto. Além disso, a riqueza da abordagem de Leupen se deve em parte ao abrangente leque de ferramentas que ele propõe para análise projetual. Além dos textos e desenhos, ele também abrange maquetes e simulações computacionais.

No que diz respeito aos desenhos, seu alcance vai além das tradicionais representações bidimensionais de plantas, cortes, e vistas, englobando também estilização destes desenhos, para revelar sua estrutura morfológica; adições, para introdução de novas informações aos desenhos; desmontagem, que se assemelha ao desenho explodido, mas permite também a justaposição entre diferentes sistemas do projeto.

Segundo Baker (2005), estes diagramas são seletivos e buscam a claridade e a comunicação, revelando assim a essência. "Podem explicar melhor a forma e o espaço que as palavras e as fotografias".

Simulações computacionais, que podem ser usadas tanto para a análise proposta por Leupen com também para análise das outras categorias, como por exemplo, o conforto climático. Seu uso, no entanto, é pouco abordado por este autor.

Com base nas ferramentas descritas acima, Leupen et al. (1999) abordam a análise em cinco tópicos, a saber: ordem e composição; projeto e uso; projeto e estrutura; projeto e tipologia; e projeto e contexto.

Em ordem e composição, Leupen et al. (1999) partem da ideia que a forma determina a qualidade do espaço e que esta é resultado da ordenação de elementos espaciais e materiais. Esses elementos espaciais podem por exemplo, ser salas, praças urbanas, etc., já os materiais incluem paredes, blocos de construção, aglomerados de árvores, entre outros. No que diz respeito à ordenação, Leupen et al. (1999) colocam três funções para a mesma: facilitar a compreensão do espaço; tornar mais eficiente sua construção; e torná-lo usável, entendendo que um sistema ordenado tende a ser mais eficiente para seus usuários.

Sobre o projeto e o uso, ele parte da relação entre o ambiente construído e o espaço real, buscando entender como as convenções e demandas sociais geradas pelo uso são traduzidas em linguagem arquitetônica. Segundo o autor, projetar o espaço não é apenas seguir os requisitos sociais em uso, mas envolve também uma interpretação destas exigências pelo projetista.

Já em projeto e estrutura, ele aborda como a tecnologia influencia a arquitetura, com ênfase em como a estrutura pode ou não determinar a forma da arquitetura. 
Em projeto e tipologia, ele ressalta a importância desse tipo de análise para prover meios de nomear e descrever como os elementos do espaço se encaixam em uma composição.

E por fim, em projeto e contexto, ele foca na relação entre o sítio, a resposta do projeto, os meios empregados e o projeto produzido.

A importância deste tipo de análise se dá justamente por sua abrangência, contemplando tanto o projeto em si como seu contexto, no entanto, como reconhece o próprio Leupen, ela carrega em si um certo grau de subjetividade. Entende-se por tanto que ela deva ser acompanhada por outras ferramentas. É nesse ponto que entram as avaliações de desempenho, pois nos permitem não apenas entender como o edifício foi concebido, mas também como tais estratégias se comportam. Seu desempenho e percepção pelos usuários.

\subsection{Avaliação pós-ocupação e sua contribuição para as análises de projeto}

A avaliação pós-ocupação (APO) pode ser definida segundo Romero (2011), como uma metodologia de avaliação que insere a figura do usuário no processo avaliativo sem, contudo, reduzir o papel da avaliação técnica e teórica.

A APO tem como objetivos fornecer recomendação para os estudos de caso e também para os futuros projetos semelhantes àqueles estudados. Na APO são consideradas as variáveis construtivas, de conforto ambiental e conservação de energia, funcionais, econômicas, estéticas e comportamentais.

A avaliação pós-ocupação (APO) possui diversos instrumentos e ferramentas, cada uma fornecendo um conjunto diferente de dados acerca de cada projeto, cabendo a quem fizer a análise optar por aquelas mais alinhados a suas necessidades.

De um modo geral ela pode ser estruturada nos seguintes tópicos: avaliação dos usuários; avaliação do técnico; diagnóstico; simulações e variações paramétricas; conclusões da APO e recomendações para o estudo de caso.

Aqui resumimos as principais ferramentas utilizadas nas avaliações dos usuários e técnicas e alguns exemplos de contribuições das mesmas para as análises de projeto.

\subsubsection{Avaliação dos usuários}

A avaliação dos usuários pode envolver: observações comportamentais; entrevistas; e tabulação dos dados. No que diz respeito às observações comportamentais, Romero (2011) sugere "que o observador não seja do tipo participativo,[...], não atue como um funcionário, e nem tampouco esteja totalmente oculto".

Dentro das avaliações focadas no usuário podemos, segundo Rheingantz et al. (2009) enumerar oito (Quadro 1).

A definição de quais ferramentas de APO podem ser utilizadas varia de situação para situação. No entanto, como exemplo, optou-se por destacar a três, bem como sua contribuição para as análises de projeto. 
O walkthrough é bastante usado na fase inicial de qualquer APO por ser de fácil aplicação e dar aos envolvidos uma visão geral das qualidades e defeitos do edifício. De forma simplificada pode ser descrito como um andar percorrendo e fazendo anotações em mapas e plantas da área a ser analisada. Segundo Rheingantz et al. (2009), o passeio walkthrough "considera as experiências e emoções vivenciadas pelos usuários e pesquisadores como 'instrumentos de medição' e de 'identificação da qualidade' dos ambientes". Por fornecer um entendimento geral de como o espaço funciona, permite escolher quais são os aspectos mais relevantes não apenas para as avaliações, mas também para as análises de projeto.

Quadro 1 - Tipos de avaliações propostas por Rheingantz et al. (2009)

\begin{tabular}{|c|c|}
\hline Ferramenta & Descrição \\
\hline Walkthrough & $\begin{array}{c}\text { Percorrer e fazer anotações em mapas e plantas da área a ser } \\
\text { analisada. }\end{array}$ \\
\hline Mapa Comportamental & $\begin{array}{c}\text { Registro sobre as atividades e o comportamento dos usuários num } \\
\text { determinado ambiente ou local. }\end{array}$ \\
\hline Poema de desejos & $\begin{array}{c}\text { Declarações por um conjunto de sentenças ou desenhos, suas } \\
\text { necessidades, sentimentos e desejos relativos também ao ambiente. }\end{array}$ \\
\hline Mapeamento visual & $\begin{array}{c}\text { Identifica a percepção dos usuários em relação a um determinado } \\
\text { ambiente. }\end{array}$ \\
\hline Mapa mental & $\begin{array}{c}\text { Elabora com desenhos e relatos de memória representações "das } \\
\text { ideias ou da imageabilidade que uma pessoa ou grupo de pessoas } \\
\text { tem de um determinado ambiente" RHEINGANTz et al (2009). }\end{array}$ \\
\hline Seleção visual & $\begin{array}{c}\text { Possibilita identificar com base em um conjunto de imagens, os } \\
\text { símbolos, as preferências e os aspectos culturais de um determinado } \\
\text { ambiente construído. }\end{array}$ \\
\hline Entrevistas & $\begin{array}{c}\text { Têm como objetivo averiguar fatos, opiniões, descobrir planos de } \\
\text { açãontimentos ou condutas. }\end{array}$ \\
\hline Questionário & $\begin{array}{c}\text { Série ordenada de perguntas relacionadas com um determinado } \\
\text { problema ou assunto, que dever ser respondido por escrito sem a } \\
\text { presença do pesquisador. }\end{array}$ \\
\hline
\end{tabular}

Fonte: Adaptado de Rheingantz et al. (2009)

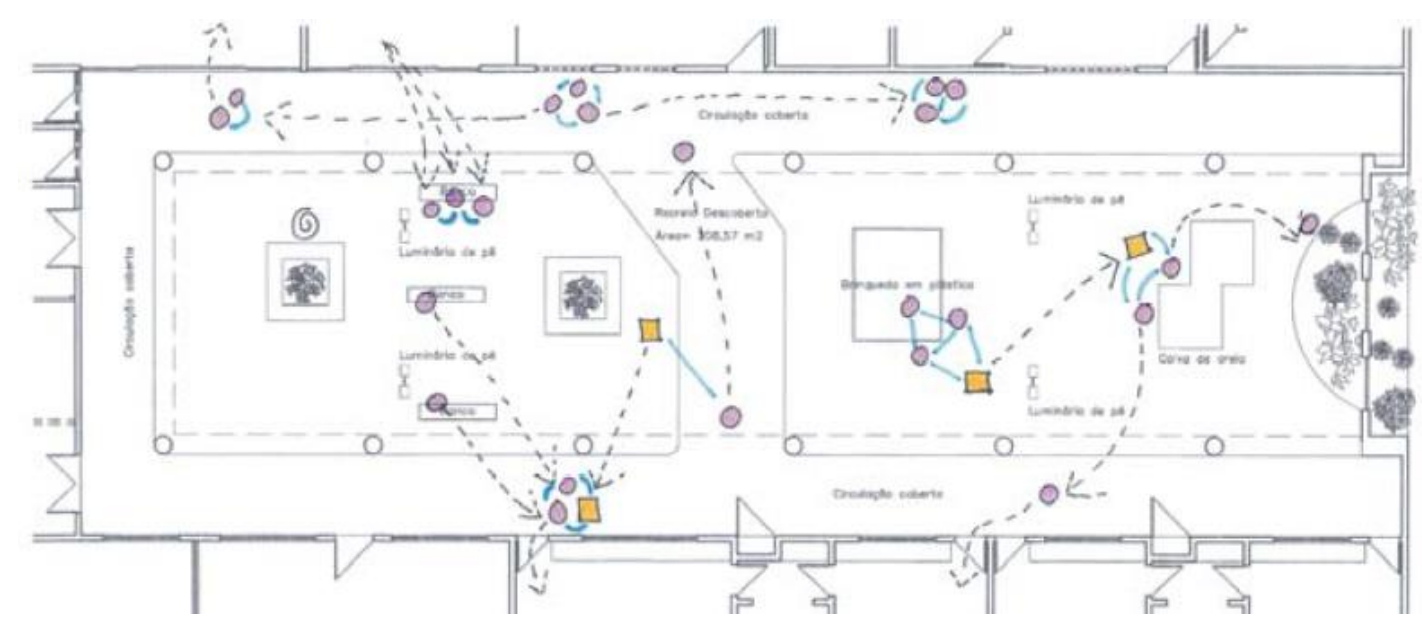

Figura 2 - Exemplo de mapa comportamental -

Fonte: RHEINGANTZ et al. (2009)

Os Mapas Comportamentais ajudam a entender como determinadas organizações espaciais encontradas nas análises de projeto se comportam em 
situações reais e a partir disso fazer paralelos entre a intenção demonstrada em projeto e seu uso. Seu principal objetivo, segundo Rheingantz et al. (2009), é o "registro das observações sobre o comportamento e as atividades dos usuários em um determinado ambiente". Ainda complementam:

\begin{abstract}
É útil para identifica os usos, os arranjos espaciais ou layouts, os fluxos e as relações espaciais observados, bem como indicar graficamente as interações, os movimentos e a distribuição das pessoas, sejam elas relativas ao espaço ou ao tempo que permanecem no ambiente considerado.
\end{abstract}

Nesse mesmo sentido temos o Mapeamento Visual, que identifica a percepção dos usuários em relação a um determinado ambiente focalizando segundo Rheingantz et al. (2009) "a localização, a apropriação, a demarcação de territórios, as inadequações a situações existentes, o mobiliário excedente ou inadequado e as barreiras, entre outras características". Foi concebido para aplicação em ambientes internos, embora também possas ser adaptado para aplicação em ambientes urbanos. A principal diferença dessa abordagem para os mapas comportamentais, é que aqui o usuário participa ativamente do processo.

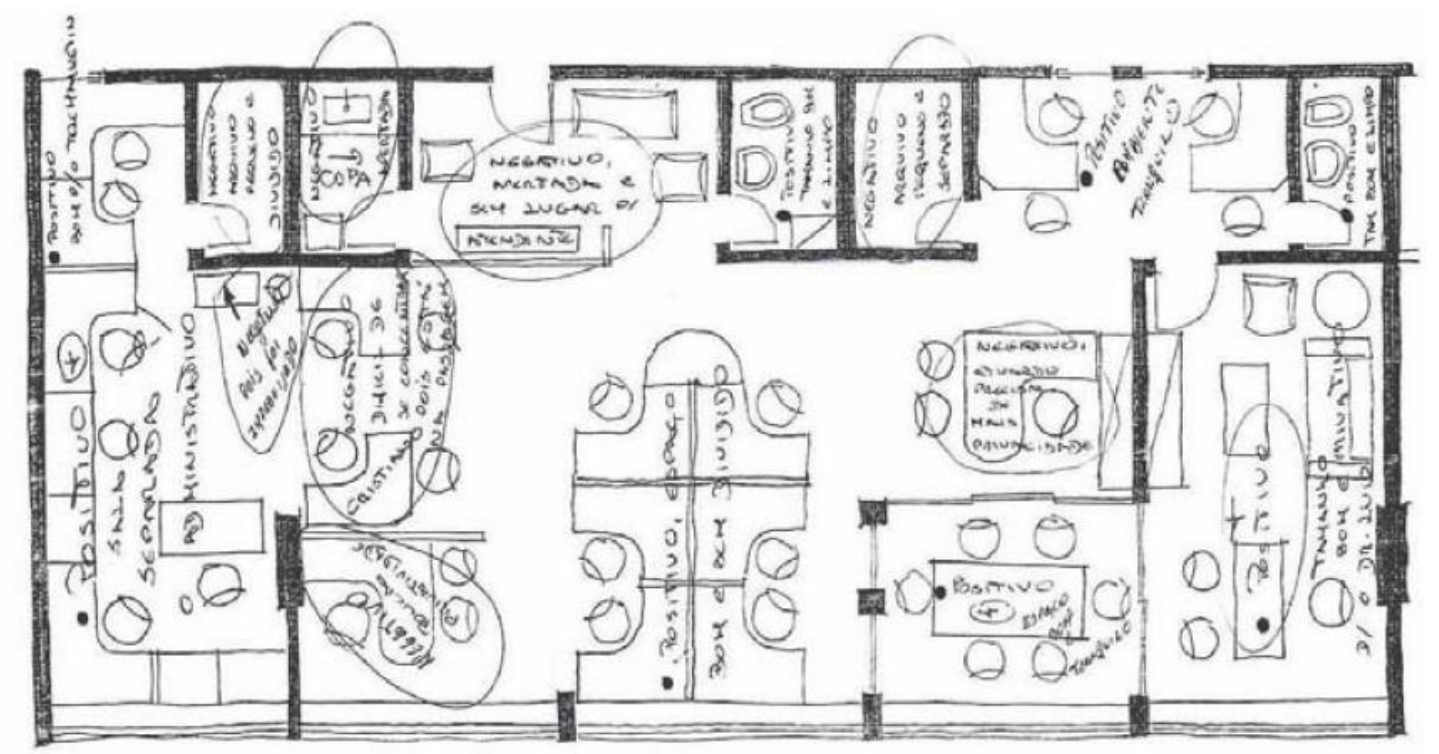

Figura 3 - Exemplo de mapeamento visual Fonte: RHEINGANTZ et al. (2009)

Estes dois últimos tópicos podem, além da análise de projeto, serem utilizados também em conjunto com as avaliações técnicas de conforto, pois lidam com percepções dos usuários.

\title{
2.2.2 Avaliação técnica
}

A avaliação técnica de APO pode abranger vários aspectos, tais como as variáveis construtivas e de conforto ambiental. A primeira abrangendo "desde as fundações ao acabamento passando por forro e vedações, indo até instalações e paisagismo" (ROMERO, 2011). Já as de conforto são focadas em informações sobre as medidas físicas do edifício, tais como iluminação natural e artificial, temperatura e umidades relativas. Aqui recomenda-se o conforto ambiental por sua ligação com outros aspectos importantes da análise de 
projeto e também da avaliação pós-ocupação. São eles a relação do projeto com o local e a percepção dos usuários no que diz respeito ao mesmo.

O termo conforto ambiental, se refere ao estado de satisfação do ser humano com o espaço em que está inserido. É aplicado a área de arquitetura de forma a abranger os temas de conforto térmico, luminoso e acústico.

O conforto térmico pode ser definido como aquele estado em que a temperatura ambiente não provoca um esforço a mais do organismo para manter a sua temperatura interna no nível apropriado para seu funcionamento. A temperatura interna para o ser humano varia, segundo Frota e Schiffer (2003), de $36,1^{\circ} \mathrm{C}$ a $37,2^{\circ} \mathrm{C}$.

Por sua vez, o conforto visual pode ser entendido com a adequação de determinado ambiente a execução de tarefas visuais pelos indivíduos. Para atender a estas condições, o conforto visual verifica as os seguintes parâmetros: lluminância suficiente; boa distribuição de iluminâncias; ausência de ofuscamento; contrastes adequados; bom padrão e direção de sombras.

Na arquitetura as principais preocupações no que diz respeito à acústica são relativas ao bloqueio ou redução de ruídos externos, e a distribuição do som por determinado recinto, este último se aplicando mais a auditórios e salas de concerto.

A contribuição deste tipo de avaliação para a análise de projeto vai desde o entendimento de como o projeto se relaciona com o contexto, ao comportamento e uso pelos usuários de determinado espaço. Seu estudo fornece fundamentação para o entendimento de certas atitudes e percepções aferidas nos mapas comportamentais e no mapeamento visual.

\section{ESTUDO DE CASO CENTRO ADMINISTRATIVO DE UBERLÂNDIA}

Para ilustrar o que foi abordado até aqui, tomemos como exemplo a praça do Centro Administrativo de Uberlândia. Ela foi concebida como uma praça cívica que articula o conjunto de edifícios do legislativo e do executivo local. Sua organização espacial favorece a visualização das manifestações e outros atos cívicos que ali aconteçam, tanto para o gabinete do prefeito quanto para o plenário da câmara (ver Figura 4).

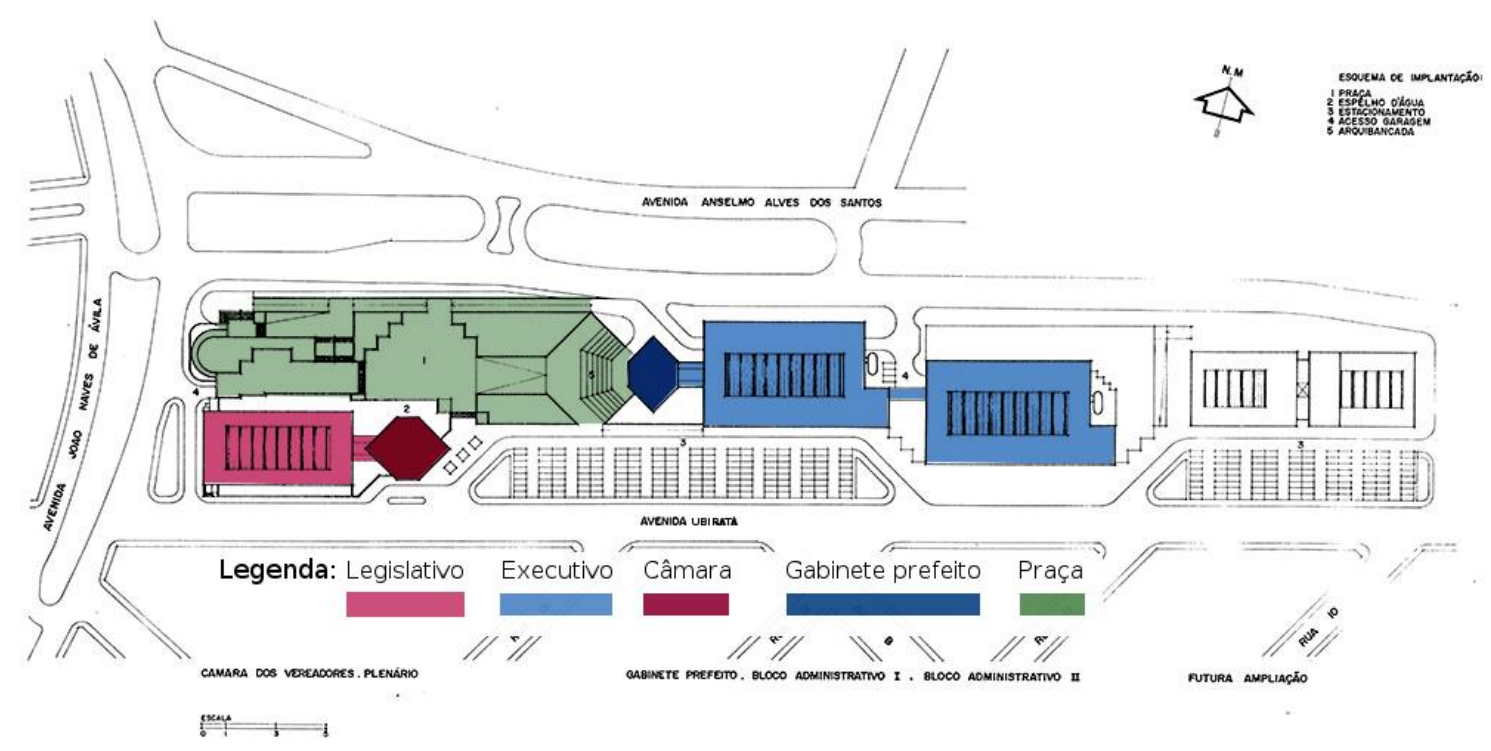


Figura 4 - Implantação conjunto de edifícios do Centro Administrativo de Uberlândia Fonte: Autor sobre imagem retirada da revista Projeto nº 1662019

Quando analisamos em projeto sua articulação com o entorno, percebemos que a mesma possuí diversos acessos, seja por rampa ou escada.

Em sua cercania temos a Av. Ubiratã como principal gerador de fluxo de pedestres, advindos sobretudo do bairro Santa Mônica. Em contra partida, a Av. João Naves apresenta a menor contribuição, uma vez que há um desnível entre ela e a praça, acarretando assim a impossibilidade de acesso por esta via. Já a Av. Anselmo Alves apresenta uma contribuição mista, uma vez que, apesar de possuir rampas que permitam o acesso à praça, a mesma não possuí um fluxo de pedestres tão elevado como a Ubiratã (ver Figura 6).

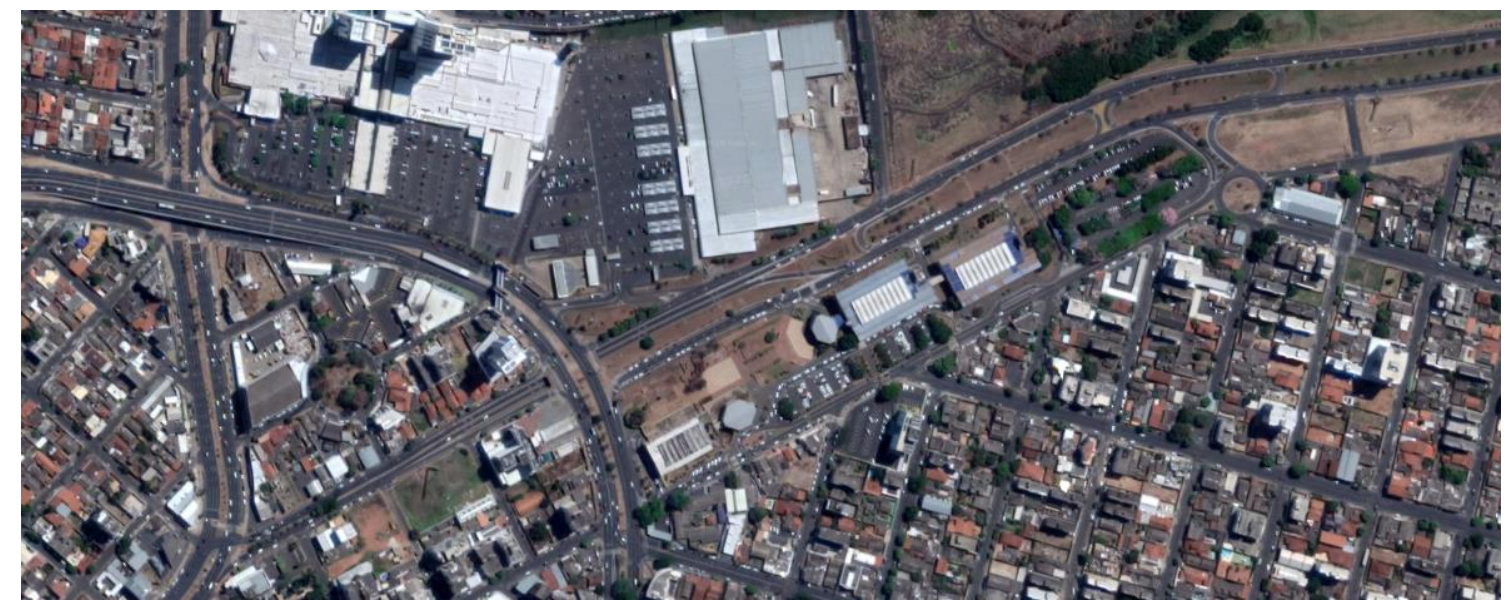

Figura 5 - Entorno Centro Administrativo de Uberlândia Fonte: Autor sobre imagem retirada do Google Maps 2019

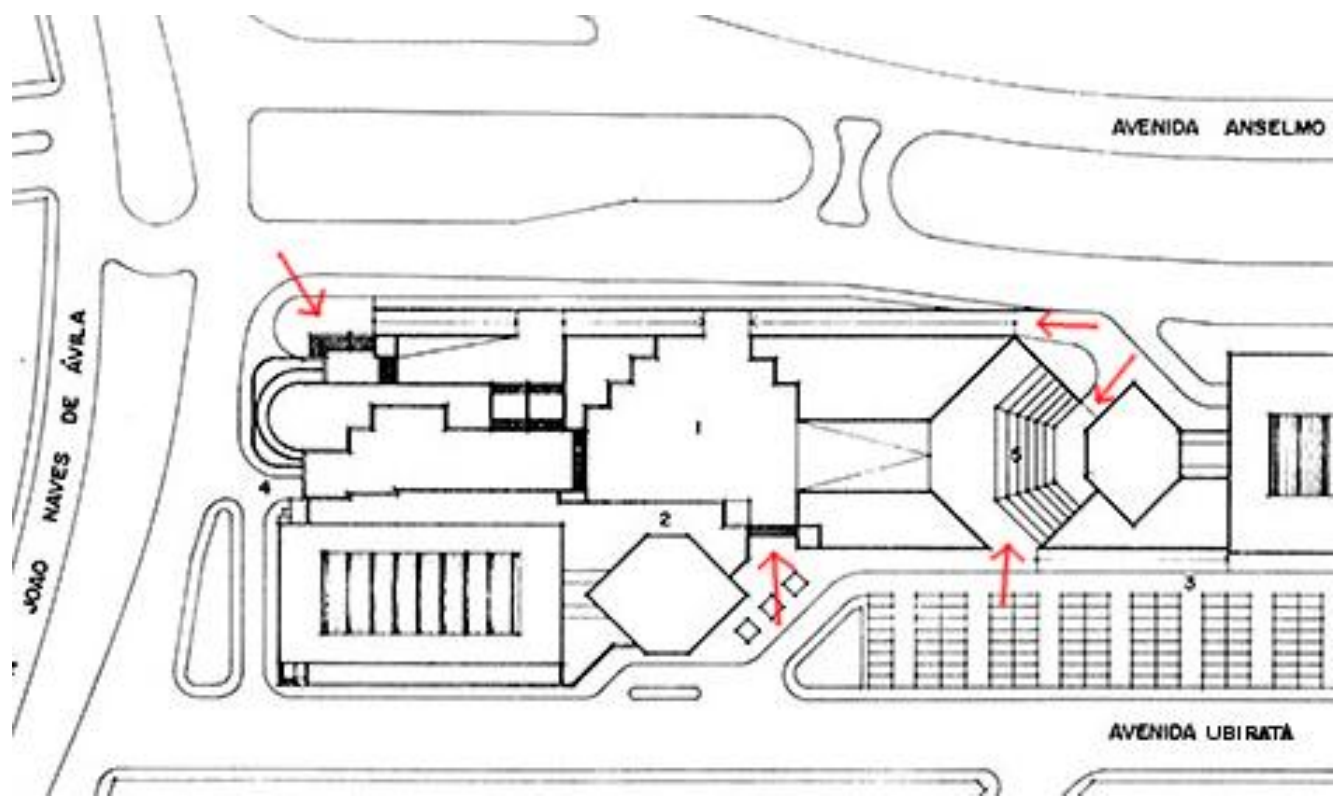

Figura 6 - Acesso praça -

Fonte: Autor sobre imagem retirada da revista Projeto nº 1662019

Ao partimos para uma avaliação do uso da praça nas condições atuais percebemos que a mesma apresenta baixo uso na maior parte do tempo. Na maioria das vezes as pessoas a utilizam apenas como espaço de ligação entre 
o bairro Santa Mônica e o complexo de shopping e supermercado existente do outro lado da avenida Anselmo Alves (no cruzamento com a Av. João Naves). Tal observação pode ser vista no mapa comportamental apresentado na Figura 7. Aqui utilizou-se desses mapas por entender que os mesmos forneciam informações relevantes acerca do comportamento das pessoas neste espaço, sobretudo a respeito de circulação e uso, além de ser uma forma menos invasiva de interagir com estes usuários.

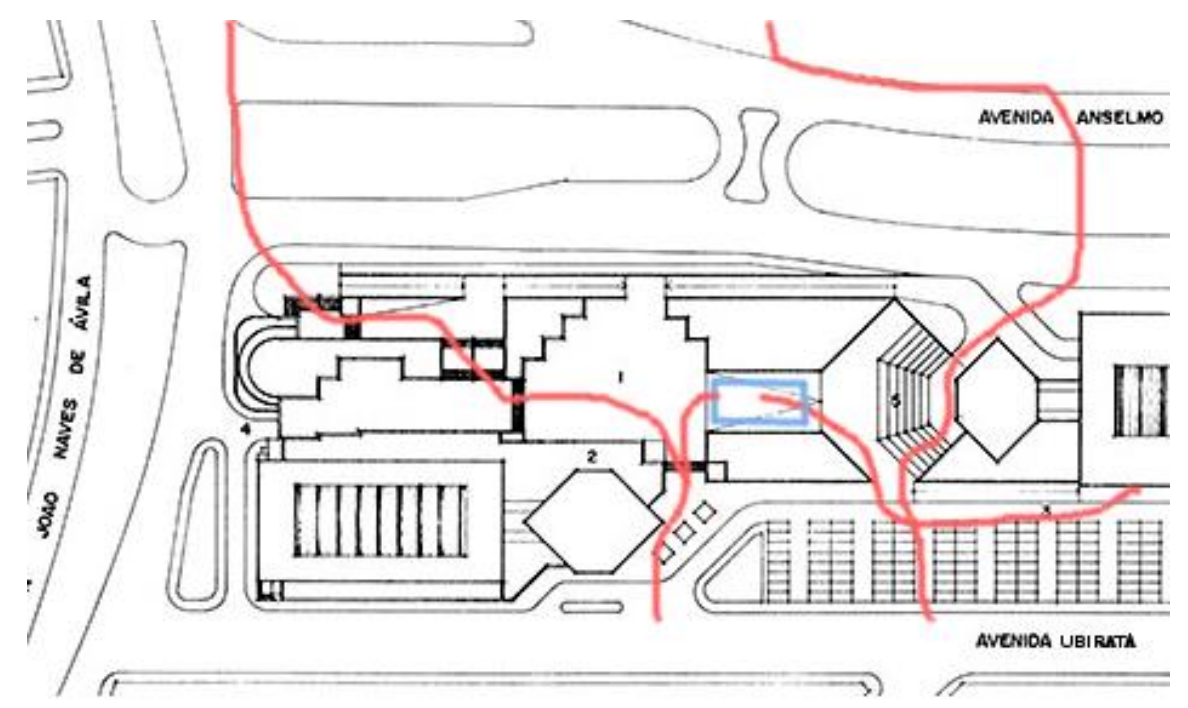

\section{Legenda:}

Caminhos mais frequentes pela praça Local da feira

Figura 7 - Mapa comportamental de praça -

Fonte: Autor sobre imagem retirada da revista Projeto n 1662019

Apesar da baixa utilização, foi observado que o espaço serve como local para algumas manifestações, como cabe a uma praça com destinação cívica. No entanto, nem sempre estas manifestações ocorrem nos locais previstos pelo projeto. Inicialmente esperava-se que eles ocorressem no espaço entre o gabinete do prefeito e a câmara dos vereadores (ver imagem 8), contudo, há casos em que estas manifestações ocorrem na entrada da câmara, por exemplo. Local este inadequado para receber grandes quantidades de pessoas. 


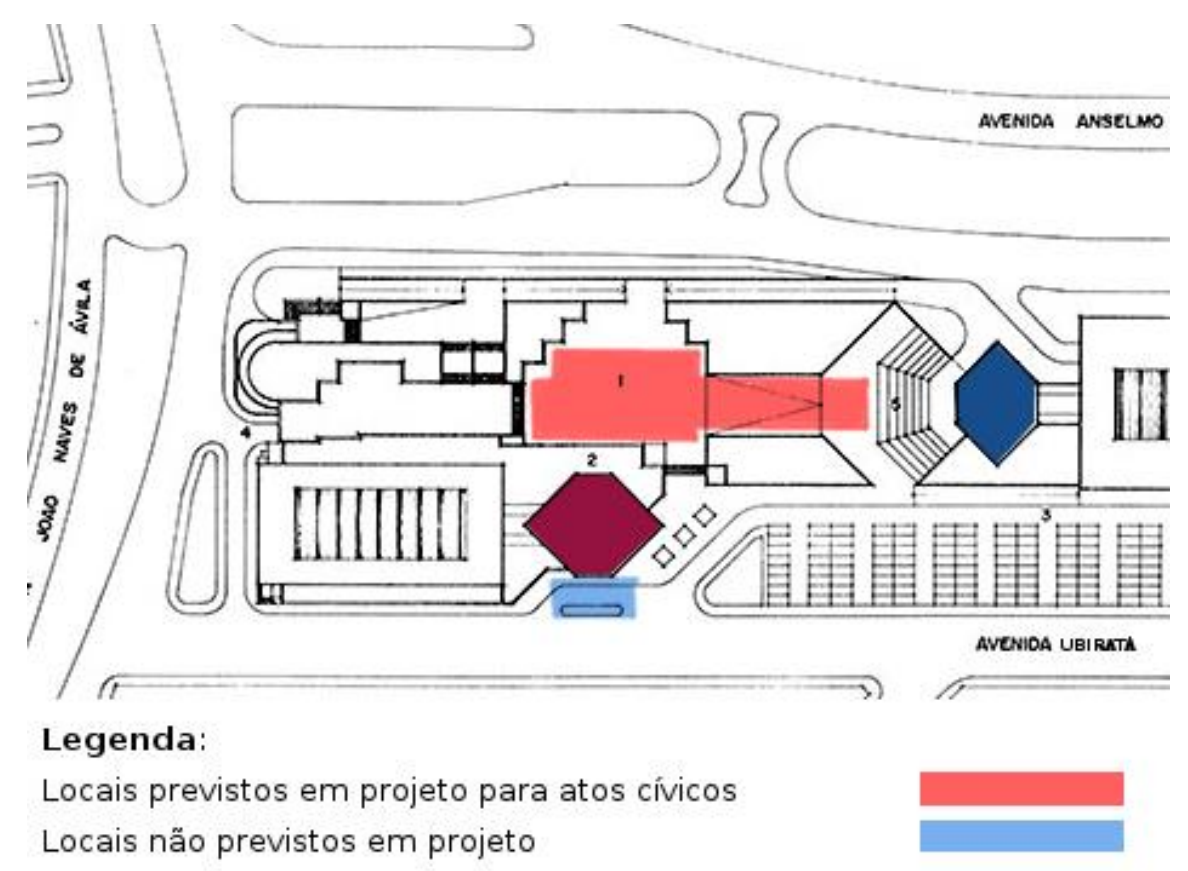

Figura 8 - Uso das regiōes da praça -

Fonte: Autor sobre imagem retirada da revista Projeto nº 1662019

Para além de seu uso cívico, a praça também recebe outros tipos de uso. 0 mais notável é a feira semanal promovida pela prefeitura municipal com pequenos agricultores locais as quartas-feiras de cada semana (ver figura 7). No entanto, vale ressaltar que tal feira é visitada muito mais pelos funcionários da prefeitura do que pelos moradores dos bairros circundantes. Além dela temos também alguns outros tipos de atividade, que ao contrário da feira ocorrem de forma espontânea. Como exemplo, podem ser citados os grupos de percussão que aproveitam o espaço no início da noite para ensaiarem. Tais apropriações ocorrem principalmente neste período do dia, em parte muito provavelmente pela falta de conforto ambiental da praça durante 0 dia.

Quando analisamos a posição da vegetação e a distribuição de bancos e outros mobiliários urbanos, vemos que os mesmos não são bem protegidos do sol como deveriam num clima quente como é o da cidade de Uberlândia na maior parte do ano. Esta avaliação colabora com a observação dos mapas comportamentais acerca da baixa utilização da praça durante o período diurno.

Como ficou exemplificado neste tópico do estudo de caso, as avaliações de pós-ocupações podem complementar as análises de projeto e contribuir para um entendimento mais amplo de como o conjunto arquitetônico e paisagístico se transforma ao longo da transição do projeto para a execução. No caso foram utilizadas ferramentas de análise de projeto voltadas para a relação do projeto com o entorno, combinadas com avaliações pósocupações através dos mapas comportamentais e das avaliações de conforto ambiental. Essa união de ferramentas e métodos nos permitiu entender como elementos do projeto se comportaram em situações reais. Revelando assim o que funcionou e quais pontos fugiram da proposta original. Tais resultados podem ser utilizados para alimentar futuros projetos que lidem com situações e climas parecidos como o apresentado aqui, e também 
contribuir para o ensino de projeto na medida em que estabelecem uma relação entre o almejado em projeto e a obra executada.

\section{CONSIDERAÇÕES FINAIS}

A proposta deste artigo é despertar a atenção para as possibilidades que se abrem ao integrar ferramentas de análise e avaliação de projeto. Para isso buscou-se nas avaliações pós-ocupação dados que não são contemplados nas análises projetuais clássicas, que se dedicam de forma resumida a uma análise espacial somente. Nestas avaliações, temos no caso da APO uma preocupação de inserção do usuário no processo sem, contudo, abrir mão de uma avaliação técnica que envolva questões construtivas, de materiais e de conforto ambiental, envolvendo neste último caso o clima e o ambiente natural para além das questões ligadas ao contexto já abordadas nas análises tradicionais de projeto.

Acredita-se que trabalhos que envolvam formas analíticas e avaliativas nos permitam uma visão mais precisa e ampla da obra arquitetônica. Com isso, propôs-se demonstrar aqui foi como estas diferentes ferramentas e metodologias poderiam ser incorporados às análises de projeto para torná-las mais abrangentes. Pretende-se que sua aplicação à análise das transformações pelas quais passou o Centro Administrativo de Uberlândia sirva de referência para futuros trabalhos semelhantes.

\section{REFERÊNCIAS}

BAKER, G. H. Análisis de la forma. Barcelona: Editorial Gustavo Gili, 2005.

CHING, F. D. K. Arquitetura - Forma, Espaço e Ordem. São Paulo: Martins Fontes, 2002.

FROTA, A. B.; SCHIFFER, S. R. Manual de Conforto térmico; arquitetura, urbanismo. 6. Ed. São Paulo: Studio Nobel, 2003. 250 p.

LEUPEN, B. et al. Proyecto y análisis - evolución de los principios em arquitectura. Barcelona: Gustavo Gili, 1999.

MAHFUZ, E. C. Nada provém do nada: A produção da arquitetura vista como transformação de conhecimento. Revista Projeto, São Paulo, n 69, p. 89-95, nov., 1984.

MAHFUZ, E. Banalidade ou correção: dois modos de ensinar arquitetura e suas consequências. Arquitextos, São Paulo, ano 14, n. 159.05, Vitruvius, ago. 2013. Disponível em:

<http://www.vitruvius.com.br/revistas/read/arquitextos/14.159/4857>. Acesso em: 04 out. 2019.

MALARD, M. L. Alguns problemas de projeto ou ensino de arquitetura. In: MALARD, M. L. (Org.) Cinco textos sobre arquitetura. Belo Horizonte: Ed. UFMG, 2005.

MIRANDA, J. T. Análise de projetos como ferramenta didática no ensino de projeto. In: V Seminário Nacional sobre Ensino e Pesquisa em Projeto de Arquitetura, Belo Horizonte, 2011. Anais da V PROJETAR 2011. Belo Horizonte: NPGAU/UFMG, 2011. 
RHEINGANTZ, P. A. et al. Observando a qualidade do lugar: procedimentos para a avaliação pós-ocupação. Rio de Janeiro: Universidade Federal do Rio de Janeiro, Faculdade de Arquitetura e Urbanismo, Pós-Graduação em Arquitetura, 2009.

ROMERO, M. A. B. (Org.) Tecnologia e sustentabilidade para humanização dos edifícios de saúde. Brasília: FAU/UnB, 2011.

' O Centro Administrativo de Uberlândia é fruto de concurso de projetos realizado em 1990, vencido pela equipe de arquitetos formada por Acácio Gil Borsoi, Milton Leite, Janete Costa, Marco Antônio Gil Borsoi e Rosa Maria Chagas Aroucha. Foi inaugurado em 1993. 